organisation of an International Air Police are insignificant compared with the difficulty of finding any practical defence scheme which has the remotest chance of becoming effective.

\section{Civil Aviation Wireless Plans}

The plans which have been approved for the establishment of new civil aviation wireless stations in Great Britain will provide for the establishment of a chain of wireless stations throughout the country, so as to afford full facilities for direction-finding, for communication with aircraft, and between airports. Three new stations came into operation last year, at Hull, Portsmouth and Newtownards (Belfast). A further six are under construction and will be placed at suitable sites during 1935 . These sites are being chosen with the object of providing a direction-finding network covering the new internal routes, as well as to serve the needs of individual aerodromes. The equipment will be mounted on vehicles capable of being easily moved from place to place. A limited number of permanent stations of higher power are also to be erected. The first of these will be established at Heston Airport to relieve the growing congestion at Croydon. It is also the intention of the local authorities to build a station in the Channel Isles. Three new permanent directionfinding stations, in addition to those already existing at the same points, are being brought into operation at an early date on the Continental airway, at Pulham, Lympne and Croydon. The radio-beacon at Croydon is now being modified to operate on the aural principle, thus making it available for any aircraft fitted with an ordinary receiver. On the completion of this reorganisation there will be available for the assistance of aircraft flying on the Continental routes seven direction finders, seven transmitters and one radio-beacon.

\section{A New Depth-Sounding Recorder}

THere are several types of marine devices for finding the depth of the sea by means of 'echosounding'. One or two of these not only give isolated indications of the depth of the sea, but also provide a more or less continuous record of the sea bed. The British Admiralty uses a low-frequency type of oscillation which is reflected from the bottom of the sea, the time of going and returning being marked on an electro-chemical recorder. A high-frequency system using the vibrations of a quartz piezo-electric oscillator, devised by Langevin and Chilowsky, has been developed commercially in Great Britain by the Marconi Sounding Device Co, An entirely new type of high-frequency echo depth recorder which possesses important advantages was described to the Institution of Electrical Engineers on January 2 by A. B. Wood, F. B. Smith and J. A. McGeachy. This device can give a continuous record of the depth of water beneath a survey motor-boat of about $2 \mathrm{ft}$. draught travelling at full speed. According to the specification, it had to measure a depth ranging up to 200 feet with a maximum inaccuracy of about one foot. The method employed gives a practical application of the phenomenon of magneto-striction. Two oscillators of this type-a transmitter.and a receiver-are mounted in water-filled tanks and fitted in a chosen position in the motor-boat. The transmitter is excited into resonant vibration at regular intervals of time depending on the range of depth to be recorded. A short train of high-frequency sound waves is directed vertically downwards to the sea-bed and reflected back to the receiver. The induced currents are amplified, rectified and passed through a recorder. During the time the sound impulse is travelling from the transmitter to the receiver via the sea bed, the recording point has travelled a corresponding distance on the paper. The time for the going and return journey is thus found. The method has been proved satisfactory for depths exceeding 400 fathoms.

\section{Vital Statistics for 1933}

LAST week (p. 181) we printed a note referring to the provisional figures of the vital statistics for 1934 . The Registrar-General's Statistical Review for 1933, Tables (Part II, Givil) is now available (London: H.M. Stationery Office. $2 s, 0 d$.). It includes a table showing the populations of England and Wales, Scotland and Ireland as enumerated at each Census from 1821 until 1931, and as estimated for each year 1894-1933 inclusive. The population of England and Wales is now estimated as 40,350,000 at the middle of 1933, the 1931 Census figure being $39,952,377$. The births registered during 1933 numbered 580,413 a decrease of 33,559 on the previous year's figure. The consequent birth rate of $14 \cdot 4$ per 1,000 population is the lowest recorded for England and Wales, being 0.9 below that for 1932 the previous lowest, and 1.4 below that for 1931. The only countries showing a lower rate in 1933 were Sweden $(13 \cdot 7)$ and Austria $(14 \cdot 3)$. The proportion of the sexes in the births registered during the year was 1,046 males to 1,000 females.

\section{Association of American Geographers}

THE thirty-first annual meeting of the Association of American Geographers, with Dr. Wallace $\mathrm{W}$. Atwood presiding, was held at the University of Pennsylvania, Philadelphia, on December 27-29. Forty-nine papers were presented, including six in the field of geomorphology, five in climatology, and two in cartography. The remaining papers ranged the whole field of geography, and included discussions of particular problems or areas. A half-day session was devoted to a conference on regional geography. As retiring president, Dr. Atwood addressed the Association on "The Increasing Significance of Geographic Conditions in the Growth of Nation States". For the fortheoming year the following officers were elected: President, Prof. Charles C. Colby, University of Chicago; Vice-President, Col. C. H. Birdseye, U.S. Geological Survey; Treasurer, Prof. John E. Orchard, Columbia University ; Councillor, Prof. Kirk Bryan, Harvard University; Secretary, Prof. Frank E. Williams, University of Pennsylvania. 